\title{
Variability in MLT dynamics and species concentrations as observed by WINDII
}

\author{
Gordon G. Shepherd, Shengpan Zhang, and Xialong Wang \\ Centre for Research in Earth and Space Science, York University, Toronto, Canada
}

(Received July 24, 1998; Revised January 8, 1999; Accepted January 8, 1999)

\begin{abstract}
Airglow variability is a topic that has been studied for decades but an understanding of the role of the dynamical influence underlying this variability has only been achieved recently. The UARS dynamics instruments, HRDI (High Resolution Doppler Imager) and WINDII (WIND Imaging Interferometer) have been instrumental in providing this understanding, because they measure both winds and emission rates, and so are able to determine the coupling between the two. But ground-based observations are also an essential ingredient to this understanding, which has grown through intercomparisons between dataset and models through workshops such as DYSMER. This presentation begins by describing the influence of the diurnal tide on oxygen and hydroxyl airglow emission rates, including the seasonal variation. This is followed by a description of two planetary scale disturbance phenomena, the springtime transition, and a stratospheric warming. Auroral influences are also considered. While these investigations cover a wide range of mechanisms there is an underlying thread which is that it is these large scale dynamical processes that are responsible for determining the distribution of the airglow patterns detected, and thus the distribution of concentration of atomic oxygen.
\end{abstract}

\section{Introduction}

Our understanding of MLT variability has expanded rapidly following the launch of NASA's Upper Atmosphere Research Satellite (UARS) as the HRDI (High Resolution Doppler Imager) and WINDII (Wind Imaging Interferometer) instruments have yielded a wealth of data on this subject. Because these instruments measure both the winds and the emission rates it has been possible to directly link the effects relating these quantities. At the same time, comparisons of HRDI and WINDII data with those obtained from groundbased and other measurements through workshops such as DYSMER have advanced the understanding of the community concerning the processes involved. A review of this subject is now a major topic, and what is presented here will be only a brief summary of recent developments. Airglow variability is a rich subject for exploration because there are decades of data available but we have only recently begun to obtain the benefits from this. Thus this paper begins with a brief discussion of the oxygen airglow, and why it is so important in relation to MLT dynamics. We then proceed to discuss this relationship in the context of tides and seasonal effects before going on to two topics focused on planetary scale disturbances, the "springtime transition" and stratospheric warmings.

The satellite data presented are all from WINDII because these data are readily available to us, and because our understanding has developed from these data (some groundbased data are also included illustrating their often crucial role in relation to satellite data). WINDII is a field-widened Doppler imaging Michelson interferometer (Shepherd et al.,

Copy right (C) The Society of Geomagnetism and Earth, Planetary and Space Sciences (SGEPSS); The Seismological Society of Japan; The Volcanological Society of Japan; The Geodetic Society of Japan; The Japanese Society for Planetary Sciences.
1993), essentially a CCD camera that views the earth's limb through a Michelson interferometer whose optical path difference (time delay) is quasi-fixed at a value large enough to make possible the measurement of Doppler shifts as small as $5 \mathrm{~m} \mathrm{~s}^{-1}$. The field-widening refers to a configuration in which refractive materials are used in the arms of the interferometer in order to make the phase vary slowly over the field of view as required for this imaging application. The interferometer modulates the incoming light so that its phase, and hence the wind, may be detected for each pixel in the image, but since it does not attenuate the light significantly the instrument is as sensitive as the CCD camera itself. The result is that WINDII can make accurate measurements of winds and emission rates from the atomic oxygen green line emission at $558 \mathrm{~nm}$ during night as well as in the daytime, including the determination of vertical profiles, even for very weak emission, including the hydroxyl airglow as well as the oxygen airglow. This large sensitivity is the key to many of the interpretations which have been made with these data.

\section{Airglow}

The processes leading to the production of atomic oxygen in the upper atmosphere, through photodissociation of $\mathrm{O}_{2}$, are well described by Tohmatsu (1990). Photodissociation in the Schumann-Runge continuum begins a little below $140 \mathrm{~km}$, and is complete by about $90 \mathrm{~km}$. The bulk of the production is above the level where the oxygen airglow is observed, so as has long been recognized, dynamical processes are required to bring the atomic oxygen down to where the atmosphere is dense enough for the photochemistry to proceed. Historically the sole dynamical process has been assumed to be small scale mixing effects. However, it will be seen that the large scale dynamics observed by WINDII must play a major role; specific mechanisms involved are described by 

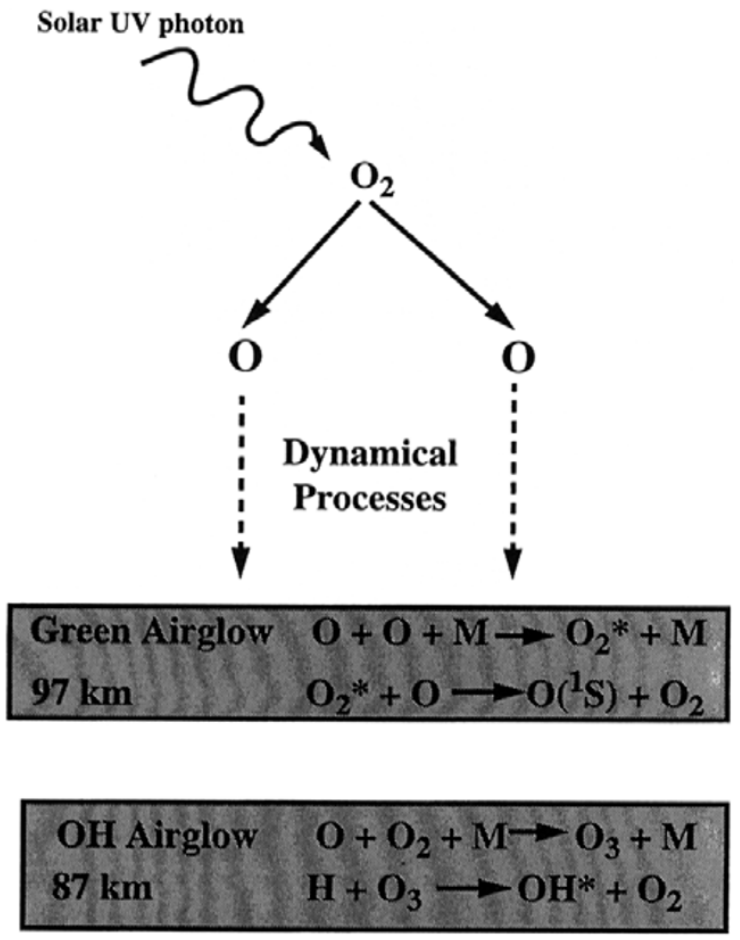

Fig. 1. Illustrating the photodissociation of molecular oxygen, the downward transport of $\mathrm{O}$ through dynamical processes, and the formation of the green line and hydroxyl airglows.

Ward (1999). For the atomic oxygen green line airglow OI $558 \mathrm{~nm}$ originating from $\mathrm{O}\left({ }^{1} \mathrm{~S}\right)$ this is a two-step process as follows (McDade et al., 1986):

$$
\begin{aligned}
& \mathrm{O}+\mathrm{O}+\mathrm{M} \rightarrow \mathrm{O}_{2}^{*}+\mathrm{M} \\
& \mathrm{O}_{2}^{*}+\mathrm{O} \rightarrow \mathrm{O}\left({ }^{1} \mathrm{~S}\right)+\mathrm{O}_{2},
\end{aligned}
$$

where $\mathrm{M}$ is a third body (most often $\mathrm{N}_{2}$ ) and $\mathrm{O}_{2}^{*}$ is an unidentified state of $\mathrm{O}_{2}$, the so-called precursor of $\mathrm{O}\left({ }^{1} \mathrm{~S}\right)$. Because the $\mathrm{O}\left({ }^{1} \mathrm{~S}\right)$ is a direct result of the recombination of atomic oxygen, the airglow is a measure of the atomic oxygen concentration; one can readily convert one to a knowledge of the other. Besides the atomic oxygen green line WINDII also observes emission from the Meinel bands of the hydroxyl radical (Fig. 1).

$$
\begin{aligned}
& \mathrm{O}+\mathrm{O}_{2}+\mathrm{M} \rightarrow \mathrm{O}_{3}+\mathrm{M}, \\
& \mathrm{H}+\mathrm{O}_{3} \rightarrow \mathrm{OH}^{*}+\mathrm{O}_{2},
\end{aligned}
$$

where $\mathrm{OH}^{*}$ is the excited state giving rise to the Meinel bands. Since these reactions are also controlled by atomic oxygen, observations of the hydroxyl airglow allow us to extend our understanding of the dynamical processes that transport atomic oxygen at lower altitudes than are accessible from the oxygen airglow.

\section{Tidal Variations}

The influence of dynamics on the airglow is readily apparent in those motions driven by the diurnal tide, especially at the equator where the effects are strong. Tidal influence on airglow emission was detected at an early stage in the analysis of UARS data (Burrage et al., 1994; Shepherd et al., 1995). The WINDII data presented by Shepherd et al. (1995) for the atomic oxygen green line consisted of vertical distributions of volume emission rates, which showed very dramatically the vertical motions of the airglow layer induced by the diurnal tide. The effects are particularly large at the equator, where, in the evening, the tidal influence pushes the layer down, and causes it to brighten. But there is a limit to this process, as the emission becomes quenched below a certain altitude, as well as the precursor, and the supply of oxygen begins to run out. For these reasons the emission almost disappears at about midnight, but then begins to reappear at a higher normal altitude as dawn approaches, and a fresh supply of atomic oxygen is introduced.

These effects were simulated with the TIME-GCM model by Roble and Shepherd (1997), in which excellent agreement with the WINDII equinox data was found with the input of a strong diurnal tide at the bottom $(30 \mathrm{~km})$ of the model. More recently, Shepherd et al. (1998) presented WINDII and ground-based comparisons with the TIME-GCM model at mid-latitudes, for both equinox and solstice. Here, the diurnal pattern of emission rate variation changes substantially between equinox and solstice, as a result of the changing relative contributions of the diurnal and semi-diurnal tide. This is consistent with the seasonal variations of these tides as shown by McLandress et al. (1996), with the diurnal tide having its maximum at equinox, and the semi-diurnal tide having its maximum at solstice.

These conclusions have now been reinforced by using emission rates for the hydroxyl emission, another airglow emission observed by WINDII that has not as yet been widely published. Figure 2 shows the latitude distribution at equinox for a) the meridional wind, b) the atomic oxygen green line airglow volume emission rate and c) the volume emission rate for the $\mathrm{P}_{1}(3)$ line (at $734 \mathrm{~nm}$ ) of the $(8,3)$ Meinel band, all for a local time of 02:00 LT (for further details see Zhang and Shepherd (1999). In Fig. 2(a), the meridional winds show the alternating character with altitude associated with the diurnal tide; inward winds (with respect to the equator) at one altitude and outwardly directed at an altitude roughly 12 $\mathrm{km}$ higher, corresponding to one half of the tidal wavelength. The symmetry of this pattern indicates the dominance of the diurnal tide at equinox. Figure 2(b) shows the equatorial minimum in emission rate that is characteristic of the local time period around midnight, a familiar feature that has been found in earlier investigations (Christophe-Glaume, 1965; Donahue et al., 1973; Reed and Chandra, 1975; Cogger et al., 1981). With respect to the equatorial minimum (actually located at $5^{\circ} \mathrm{N}$ ) of 84 photons $\mathrm{cm}^{-3} \mathrm{~s}^{-1}$ there are maxima at $35^{\circ} \mathrm{S}$ and $30^{\circ} \mathrm{N}$, with peak emission rates of 171 and 141 photons $\mathrm{cm}^{-3} \mathrm{~s}^{-1}$ respectively. The hydroxyl emission is shown in Fig. 2(c) and here we see a maximum rather than a minimum. This can be understood in terms of the fact that the green line airglow at the equator is at $97 \mathrm{~km}$, which is $12 \mathrm{~km}$ higher than the hydroxyl emission altitude of 85 $\mathrm{km}$ and thus one-half wavelength of the diurnal tide as determined from the WINDII meridional wind pattern of Fig. 2(a), or from more extensive measurements made by others e.g. 
(a)

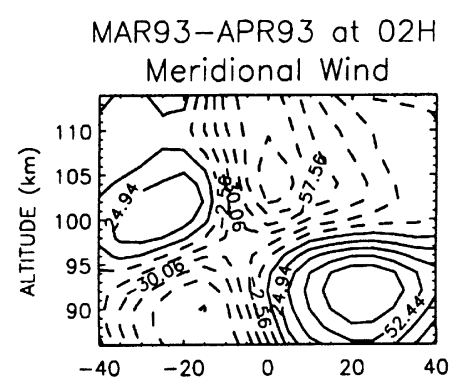

(b)
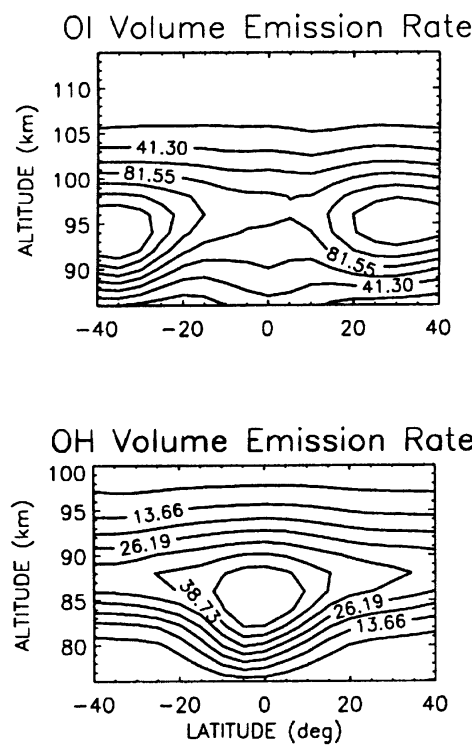

Fig. 2. WINDII data for equinox, March/April 1993, for 02:00 LT, showing (a) the meridional wind in $\mathrm{m} \mathrm{s}^{-1}$ where solid and dashed contours indicate respectively northward and southward directions, (b) the atomic oxygen green line emission rate in photons $\mathrm{cm}^{-3} \mathrm{~s}^{-1}$, and (c) the hydroxyl volume emission rate in the same units.

McLandress et al. (1996). Thus it is to be expected that the green line and hydroxyl emissions should be out of phase. This is true at the equator but not necessarily elsewhere as the altitude of the airglow layers varies with latitude; the peak volume emission rate for the green line at $35^{\circ} \mathrm{S}$ is at 94 $\mathrm{km}$, while the altitude for the $\mathrm{OH}$ emission peak is $88 \mathrm{~km}$ at mid-latitudes, a difference between the two of only $6 \mathrm{~km}$.

The situation changes significantly at solstice, as shown in Fig. 3. In Fig. 3(a) it can be seen that the symmetry in the meridional wind pattern that existed at equinox is not now as well defined, indicating the change resulting from the greater role of the semi-diurnal tide. This change does not affect the equatorial green line emission pattern profoundly, as the emission there still has a minimum at $5^{\circ} \mathrm{N}$, but the volume emission rate has dropped from 85 photons $\mathrm{cm}^{-3} \mathrm{~s}^{-1}$ to 48 , a reduction of $60 \%$. The peak volume emission rates are also lower at the mid-latitude maxima; 163 photons $\mathrm{cm}^{-3} \mathrm{~s}^{-1}$ at $40^{\circ} \mathrm{S}$, a drop of $5 \%$ in the summer hemisphere, and 104 photons $\mathrm{cm}^{-3} \mathrm{~s}^{-1}$ at $40^{\circ} \mathrm{N}$, a drop of $25 \%$ in the winter hemisphere. These maxima have moved so that they are now $15^{\circ}$ of latitude farther apart than they were at equinox. For the hydroxyl solsticial airglow, there is a much more drastic change
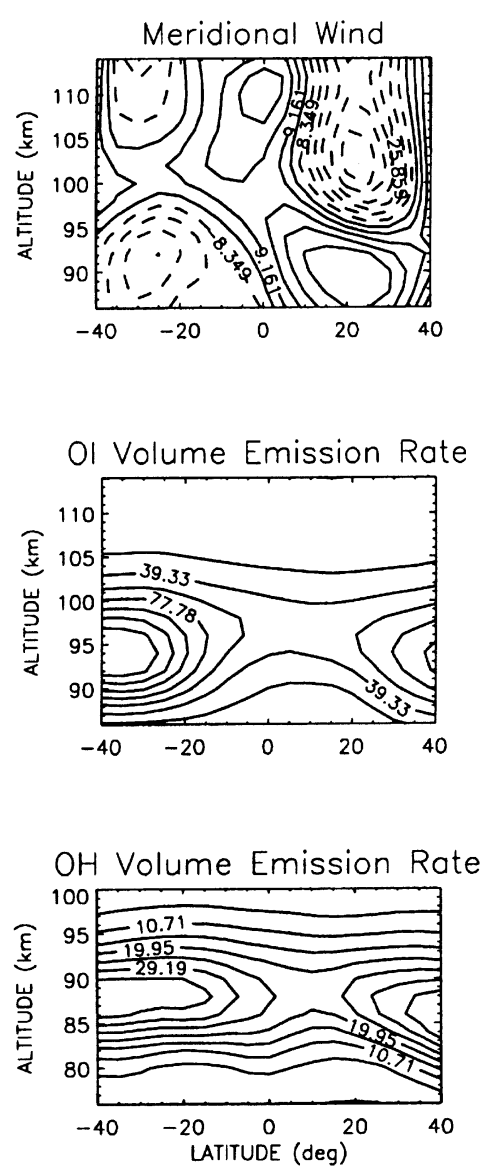

Fig. 3. WINDII data for solstice, Dec. 1993-Feb. 1994, for 02:00 LT, showing (a) the meridional wind, (b) the atomic oxygen green line emission rate, and (c) the hydroxyl volume emission rate. For units see the caption for Fig. 2.

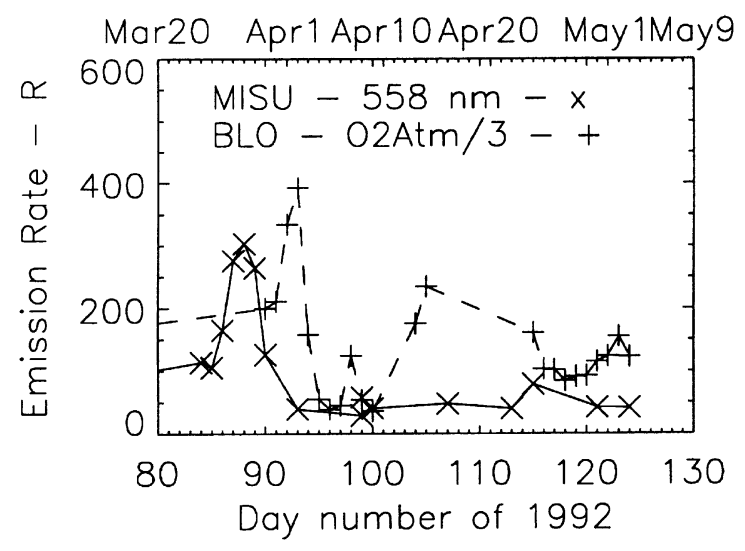

Fig. 4. Oxygen airglow emission rate at Stockholm and Bear Lake for the springtime of 1992 showing springtime pulses at both locations.

in the pattern, as a minimum has replaced the maximum that was there at equinox. The reduction in emission rate at the equator is from 55 photons $\mathrm{cm}^{-3} \mathrm{~s}^{-1}$ to 22 , a decrease of $40 \%$. At mid-latitudes the corresponding increases in emission rate are much less, $8 \%$ in the southern summer hemisphere, and 


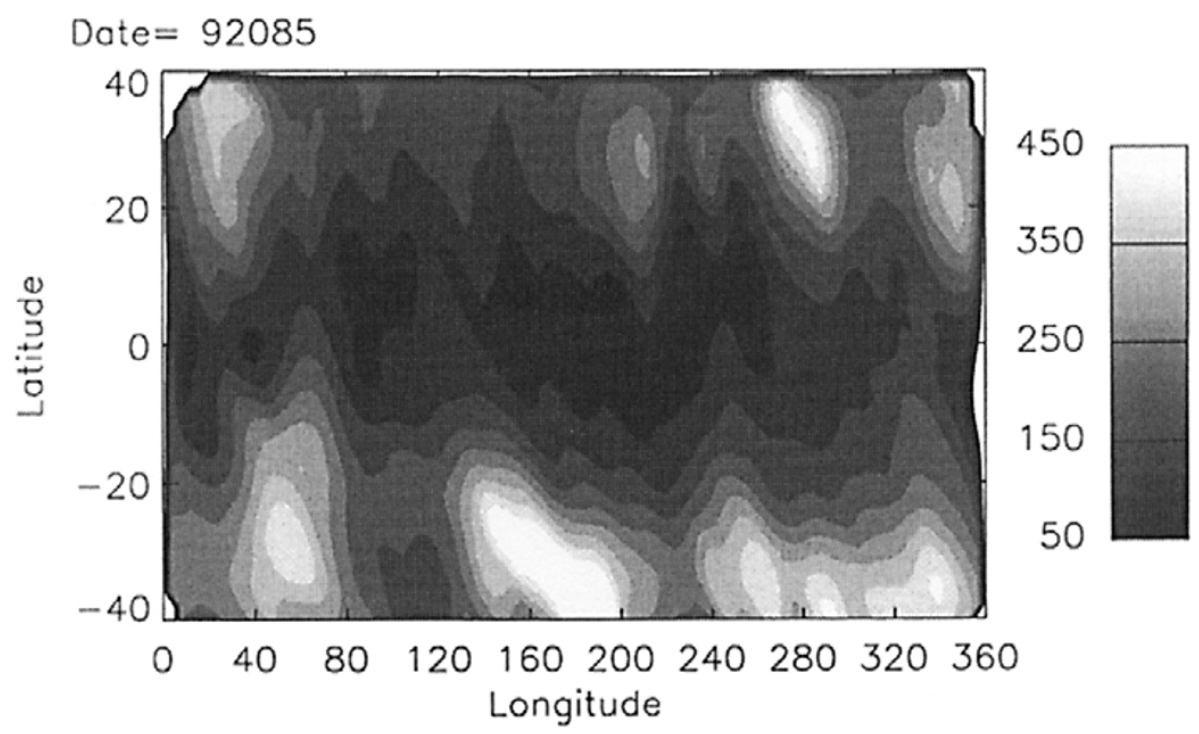

Fig. 5(a). Vertically integrated (zenithal) emission rate for the $\mathrm{O}\left({ }^{1} \mathrm{~S}\right) 558 \mathrm{~nm}$ airglow measured by WINDII for March 25 , 1992 . The bar indicates the emission rate in $\mathrm{R}$.

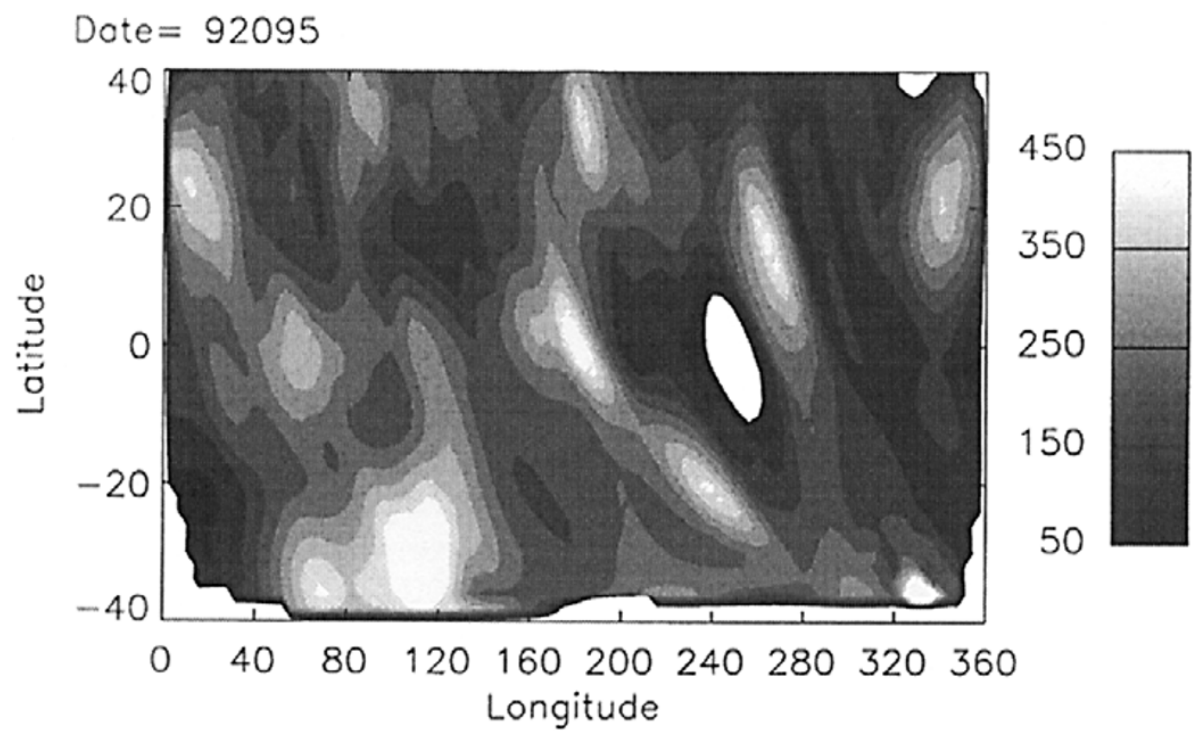

Fig. 5(b). Vertically integrated (zenithal) emission rate for the $\mathrm{O}\left({ }^{1} \mathrm{~S}\right) 558 \mathrm{~nm}$ airglow measured by WINDII for April 4, 1992, showing planetary scale structures crossing the equator.

$25 \%$ in the northern winter hemisphere. The altitude of the hydroxyl emission at the equator is now $89 \mathrm{~km}$, so that the two airglow layers are only $8 \mathrm{~km}$ apart here. Our interpretation of this dramatic effect of the seasonal variation on the airglow emission rate patterns is that this smaller distance compared with a longer wavelength of the tide as shown in Fig. 3(a) has now altered the perturbations of the two airglow layers at solstice to be more in-phase than out-of-phase, with the result that both have a minimum at the equator.

In summary, the airglow volume emission rates are an extremely sensitive indicator of tidal influence, and clearly show the control of the diurnal tide and its seasonal variability at the equator. The behavior is consistent with models of tidal behavior (Roble and Shepherd, 1997; Shepherd et al., 1998; Yudin et al., 1998). In addition diagnostic modeling by Angelats i Coll and Forbes (1998) has shown that it is the vertical wind associated with the diurnal tide that is the primary agent for the emission rate perturbations. Ward (1999) discusses the causative mechanisms in more detail, pointing out that the diurnal tide drives the vertical motion of air parcels, carrying air of higher atomic oxygen mixing ratio into regions where the mixing ratio is relatively lower.

\section{The Springtime Transition}

The springtime transition has been described by Shepherd et al. (1999). The original discovery was made by Stegman 

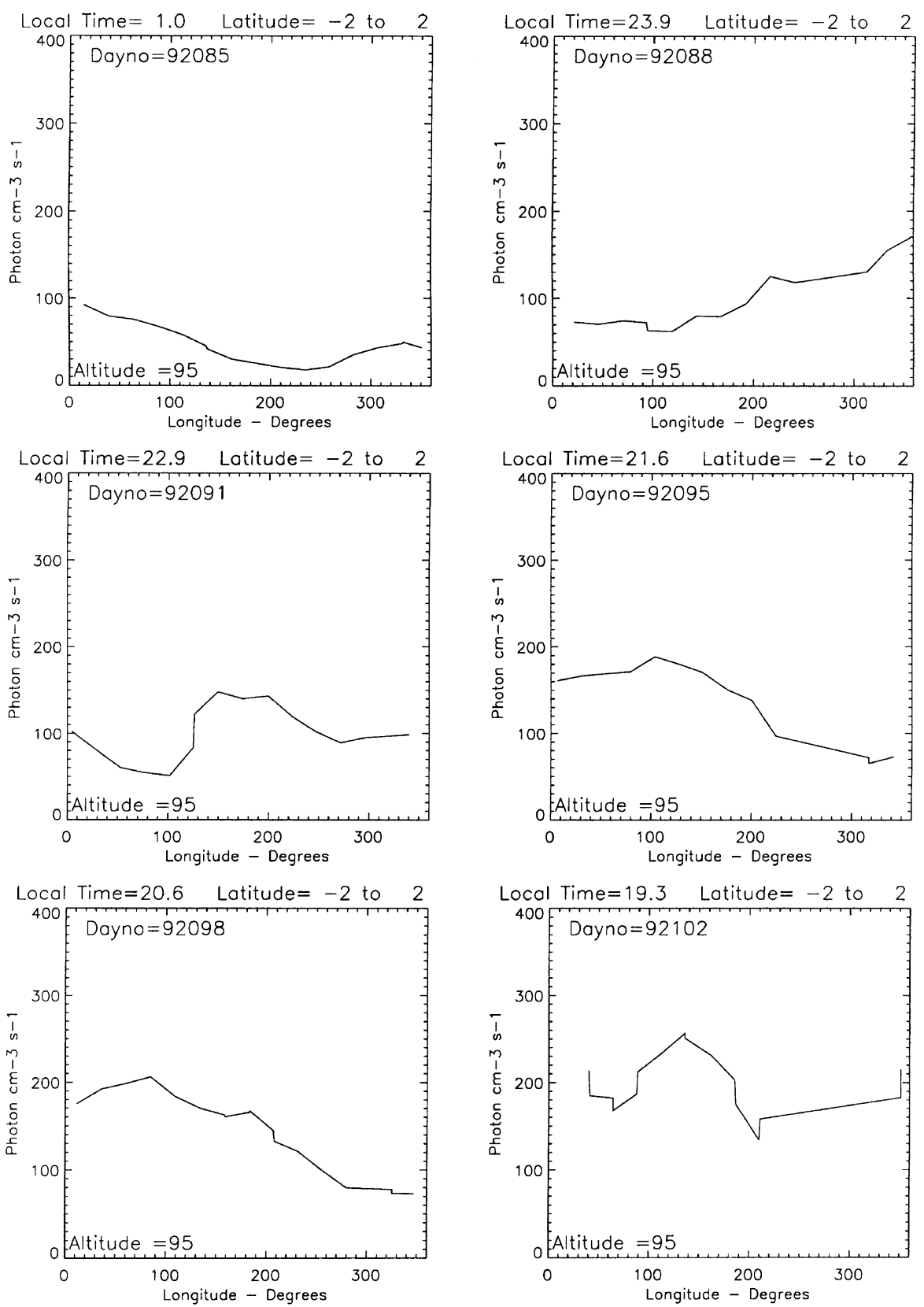

Fig. 6. OI $558 \mathrm{~nm}$ volume emission rate (photons $\mathrm{cm}^{-3} \mathrm{~s}^{-1}$ ) at $95 \mathrm{~km}$ versus longitude at the equator for six days during the northern springtime transition of 1992, March 25 to April 14.

(1992) using ground-based airglow measurements made at Stockholm, $60^{\circ} \mathrm{N}$. At high latitudes, the overall effect is a reduction in the atomic oxygen green line integrated emission rate from its wintertime fluctuations around a mean level of roughly $150 \mathrm{R}$ to a low summer value of around $20 \mathrm{R}$. This drastic reduction takes place in roughly 7 days, during which time the emission rate may rapidly rise to $300 \mathrm{R}$ or more, before falling to the summertime value, creating a pulse in emission rate that separates the winter and summer periods. The hydroxyl airglow shows the same pulse, in both emission rate and rotational temperature, but these values are not lower in summer than in winter; at these altitudes the transition appears simply as a transient, not a change of state. Thus the transition appears to mark a change in the atomic oxygen concentrations in the lower thermosphere according to the prevailing circulation, from winter to summer, but not reaching mesopause levels.

At mid-latitudes, such as Bear Lake, Utah, $42^{\circ} \mathrm{N}, 212^{\circ} \mathrm{E}$, the pulse is also seen, as shown in Fig. 4, where daily averaged values of green line emission rate from the Meteorological Institute of Stockholm University (MISU), $60^{\circ} \mathrm{N}, 20^{\circ} \mathrm{E}$, are plotted along with emission rates from the $(0,1) \mathrm{O}_{2}$ Atm band obtained from Bear Lake. Both show similar pulses as already described, with a time delay of 5 days between the two locations. The emission rate at Bear Lake behaves differently in that while it shows highly depleted atomic oxygen values after the springtime pulse, as does Stockholm, the values do not remain at a consistently low level, but rise again 
after a few days, only to fall again a few days later.

WINDII data were examined in order to explore the global pattern of airglow variation during the transition. It was found that before the transition the isophotes of constant integrated emission rate for a given altitude tended to be aligned parallel to the equator, consistent with the nighttime equatorial minimum as described in the discussion on tides. Superimposed on these parallel isophotes are localized midlatitude enhancements as shown in Fig. 5(a) near $30^{\circ} \mathrm{S}$ for March 25, 1992, prior to the transition. The planetary waves which form during the transition cut across the equator, resulting in isophotes that have much more of a north-south alignment. These planetary-scale patterns change rapidly from day to day, and it is their movement over individual ground stations which appears to cause the impulsive events. A day having such alignments is shown in Fig. 5(b), April 4, 1992. Another way of delineating these planetary waves is to make daily plots of volume emission rate versus longitude for a given latitude, and given altitude. For a single day, all data from a given latitude are characterized by the same local time for all northbound passes (and a fixed but different local time for southbound passes), so that any variations in longitude cannot be a result of the effect of the migrating tide, but must be either a true longitude variation (in the sense of being fixed to the rotating earth), or a result of a change in universal time, i.e. a true temporal change. Or it can be both. In Fig. 6 we show six such panels for the period covering the transition in 1992 . For the waves at $40^{\circ} \mathrm{N}$ see Shepherd et al. (1999), but here we show the planetary scale structures at $0^{\circ}$, clearly showing that these waves cross the equator.

For March 25, 1992 (day 92085) as shown in the upper left panel of Fig. 6, the emission rate is low everywhere, as expected for the equator and the local time of 01:00. A wave 1 is evident in the longitudinal variation, with a peak volume emission rate of 100 photons $\mathrm{cm}^{-3} \mathrm{~s}^{-1}$ near $0^{\circ}$ longitude, and a value near $20 \mathrm{R}$ at $240^{\circ}$ longitude. Three days later (upper right panel) the smooth wave 1 pattern is still present, but the emission rates have risen on average by more than a factor of 2. On day 92091 (March 31) the pattern has changed, showing a feature that is more localized in longitude; this is one of the planetary scale structures that cross the equator. The pattern begins to restore itself in the following days; the emission rate remains high but by the last panel the local time has reached the evening hours so that this may be contributing to the higher emission rate. In summary, the effects of the springtime transition are evident at the equator so that it is a truly global phenomenon.

\section{High Latitude Planetary Scale Disturbances}

The technique used in the previous section of plotting dynamical quantities versus longitude for a given day is a powerful way to study planetary scale disturbances. In this section we apply the same method to the hydroxyl and atomic oxygen green line emission at high latitudes. Figure 7(a) shows a plot for the hydroxyl emission for Feb. 15, 1993, for a latitude band centered near $50^{\circ} \mathrm{N}$. The plot has been constructed to show the volume emission rate at a fixed altitude, in order to detect emission rate changes resulting from movements in altitude of the layer; which in turn makes evident the influence of vertical motions. It has the form of wave 1 , with a peak

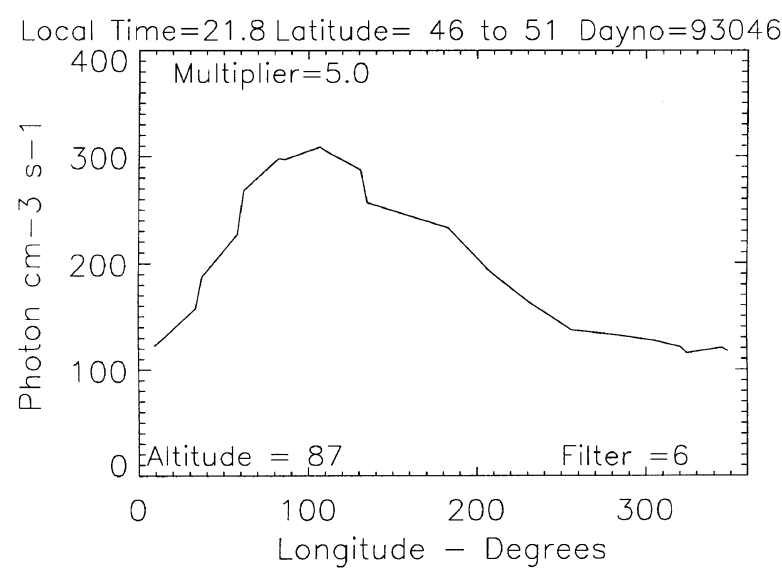

Fig. 7(a). Hydroxyl volume emission rate at $87 \mathrm{~km}$ versus longitude for February 15, 1993.

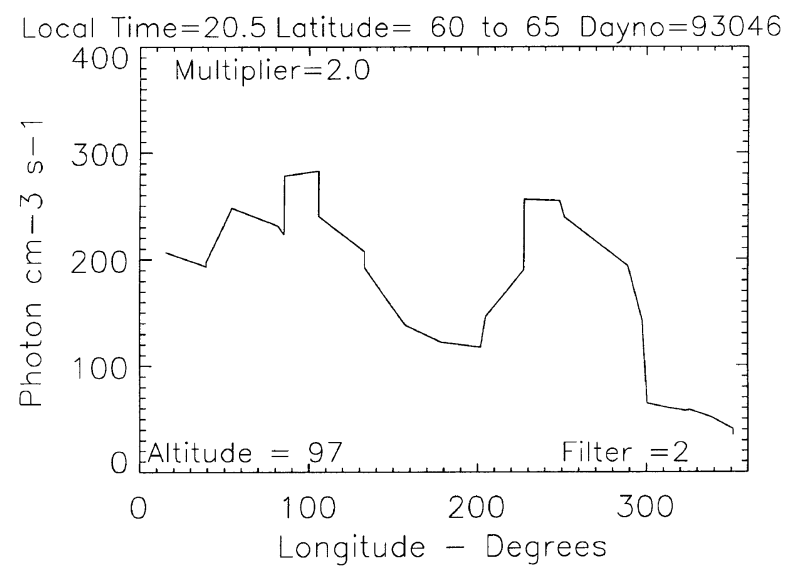

Fig. 7(b). Green line volume emission rate at $95 \mathrm{~km}$ versus longitude for February 15, 1993.

near $100^{\circ}$ longitude. On this day WINDII was programmed to make hydroxyl observations at low and mid latitudes, and to observe atomic oxygen green line at high northern latitudes with the objective of auroral measurements. Thus for the same day we are able to show, in Fig. 7(b), a green line plot for the same day for a latitude band of $60^{\circ}-65^{\circ} \mathrm{N}$. It has the form of wave 2 , with one peak near $100^{\circ}$ longitude, the other near $240^{\circ}$. A reasonable working hypothesis is that the green line and hydroxyl waves at $100^{\circ}$, even though observed at somewhat different latitudes, have a common origin, and that the green wave at $240^{\circ}$ is produced through another process. To explore this, individual vertical profiles for two different longitudes are plotted in Fig. 8, for $105^{\circ}$ longitude in Fig. 8(a), and for $251^{\circ}$ longitude in Fig. 8(b); the two profiles are totally different. For $100^{\circ}$, the location of the waves common to hydroxyl and green line, the profile of Fig. 8(a) shows a normal though rather intense airglow profile with a peak emission rate of 300 photons $\mathrm{cm}^{-3} \mathrm{~s}^{-1}$. Some emission is evident between 140 and $250 \mathrm{~km}$ altitude; this is F-region emission showing a slightly enhanced ionosphere, perhaps 


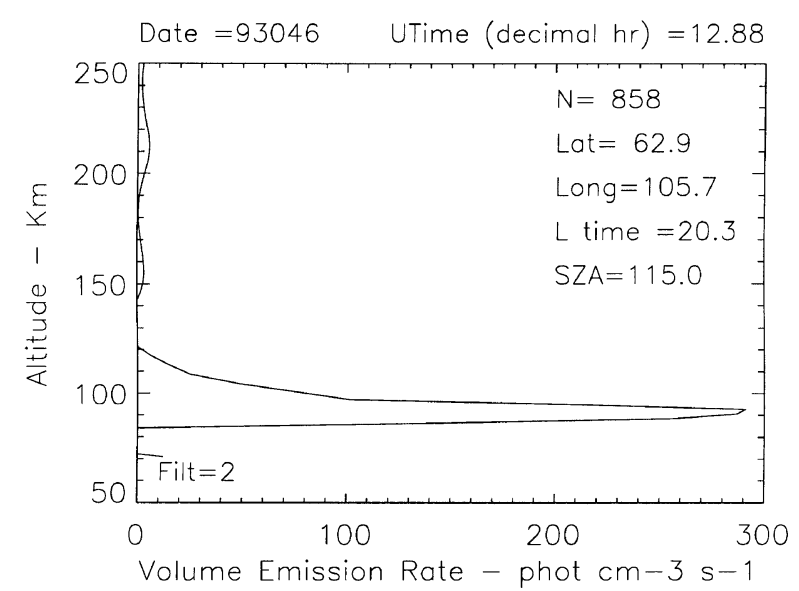

Fig. 8(a). Green line emission rate profile for February 15, 1993 at $100^{\circ}$ longitude and $63^{\circ} \mathrm{N}$.

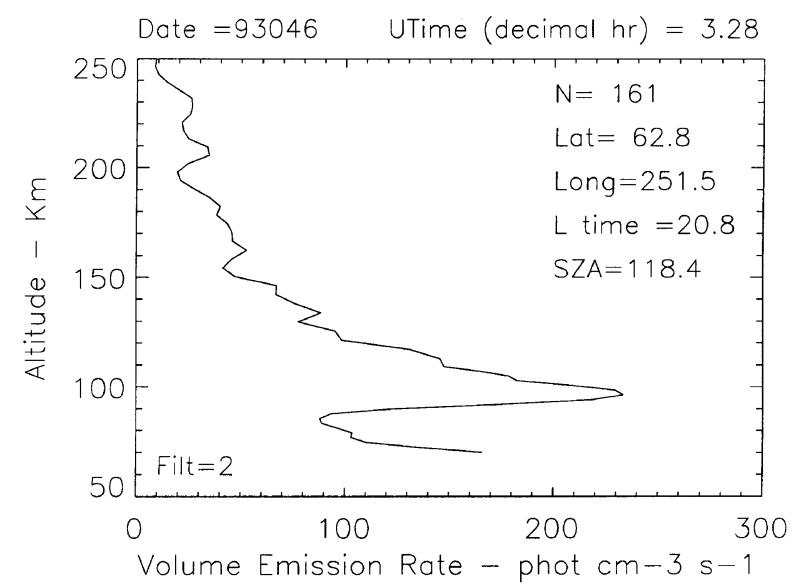

Fig. 8(b). Green line emission rate profile for February 15, 1993 at $295^{\circ}$ longitude and $63^{\circ} \mathrm{N}$, a profile that is dominated by aurora.

associated with polar cap ionospheric patches. The volume emission rate errors are much smaller than these F-region features; standard deviations are about 1 photon $\mathrm{s}^{-2} \mathrm{~cm}^{-3}$. A profile of the volume emission rate standard deviation has been shown by Shepherd et al. (1997), along with another example of F-region green line emission. The profile of Fig. 8(b) is completely different, and is characteristic of aurora. For a discussion of auroral profiles the reader is referred to the paper by M. Shepherd et al. (1996). The longitude of $250^{\circ}$ corresponds to the longitude of the magnetic pole so is where the aurora has its greatest equatorward extent in geographic coordinates. Airglow emission may be present in this profile; it cannot be distinguished from the dominant auroral profile, but it is clear that the airglow volume emission rate must be much less than in Fig. 8(a). These two profiles confirm that the wave 1 with its peak near $100^{\circ}$ longitude is an airglow phenomenon, while the second peak near $240^{\circ}$ in the green line data is due to aurora.

On February 16, there were only green line data, which are shown in Fig. 9. The peak emission rate at $100^{\circ}$ longi-

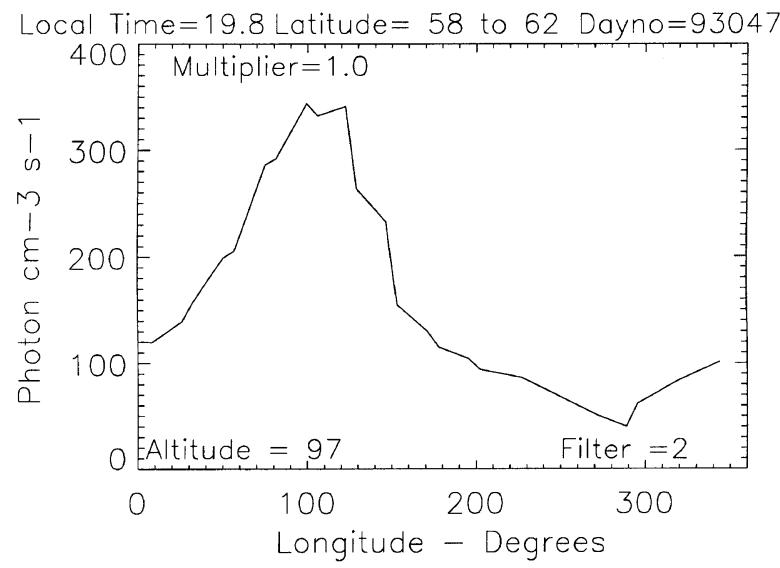

Fig. 9. Green line volume emission rate at $95 \mathrm{~km}$ versus longitude for February 16, 1993.

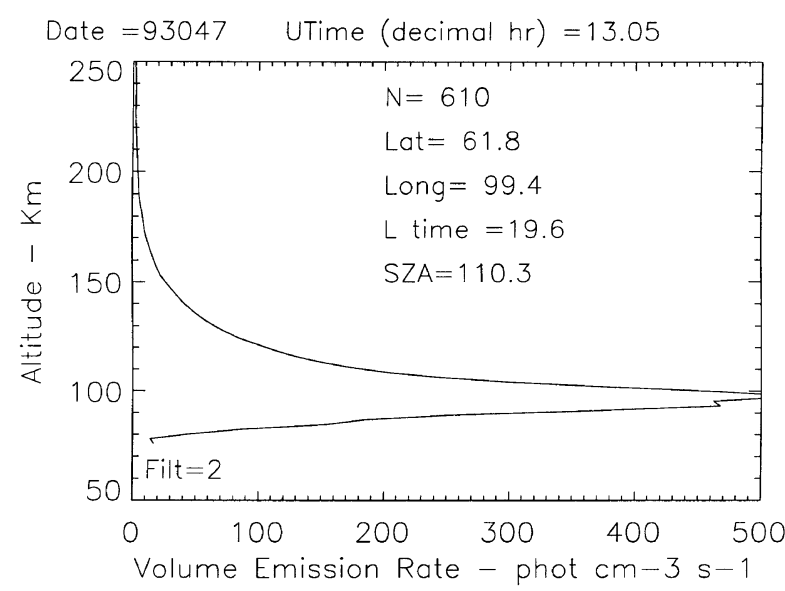

Fig. 10(a). Green line emission rate profile for February 16, 1993 at $99^{\circ}$ longitude and $62^{\circ} \mathrm{N}$, at the peak of the planetary wave 1 feature.

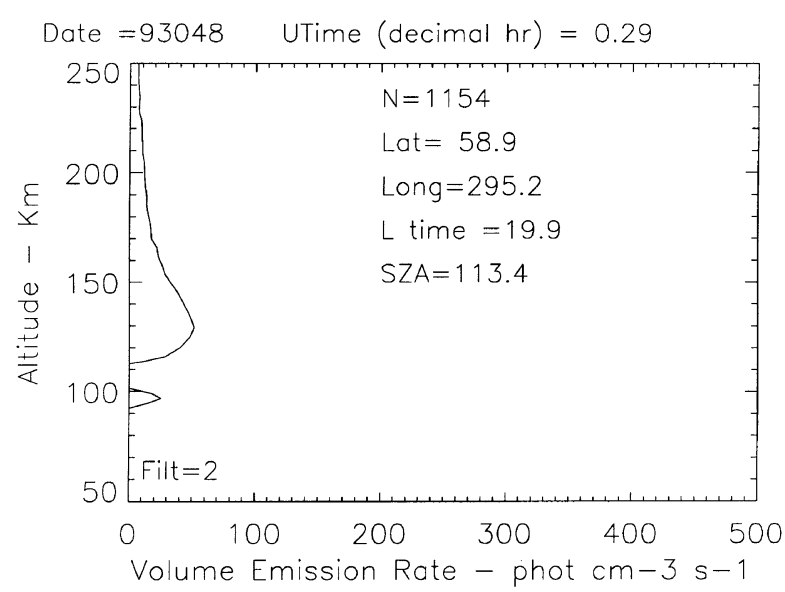

Fig. 10(b). Green line emission rate profile for February 16, 1993 at $295^{\circ}$ longitude and $59^{\circ} \mathrm{N}$, at the valley of the planetary wave 1 feature, showing aurora with airglow beneath it. 


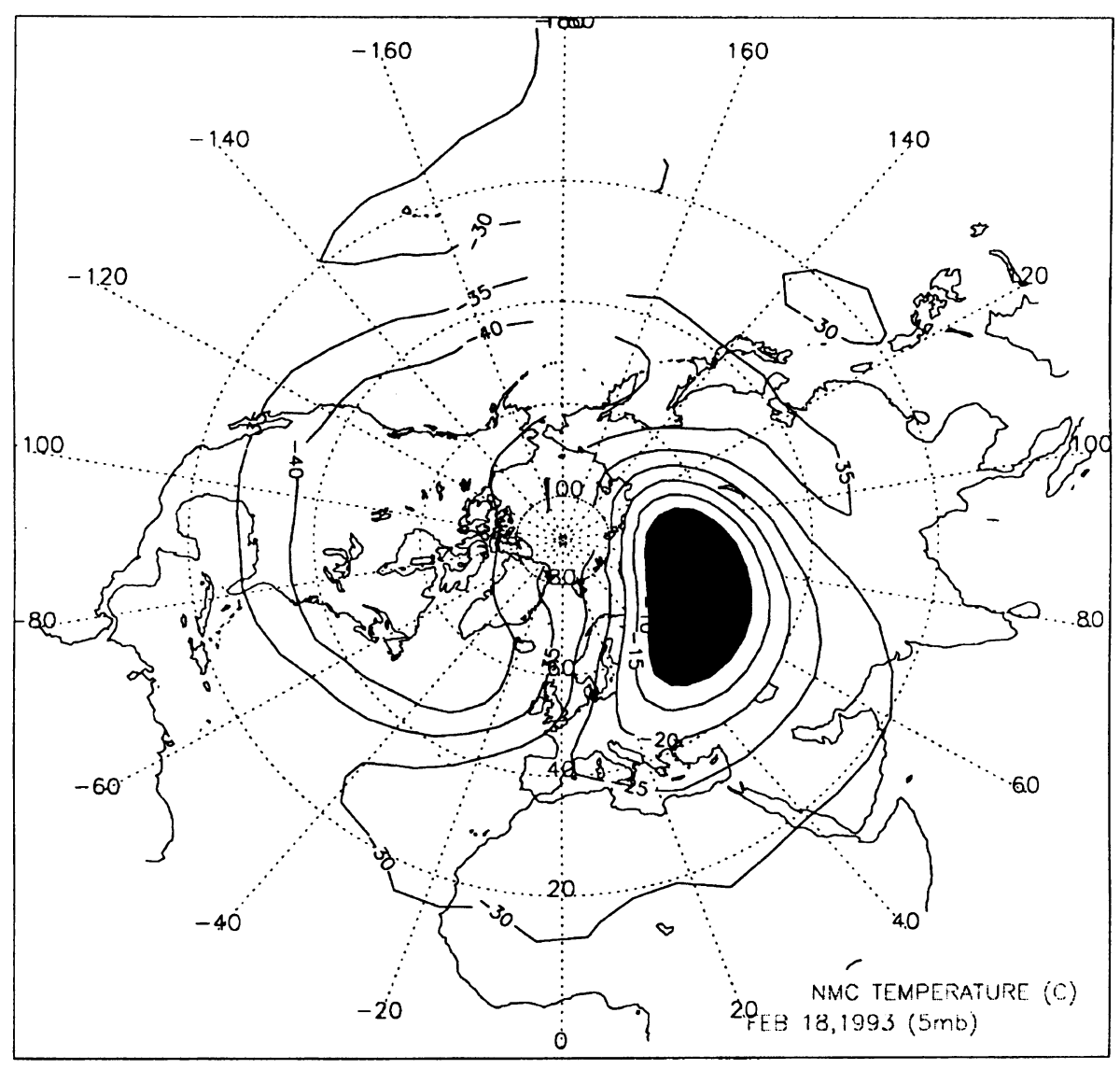

Fig. 11. NMC temperatures for $5 \mathrm{hPa}$ for February 18, 1993, showing a stratospheric warming near $70^{\circ}$ longitude.

tude has increased somewhat, from about 250 to 350 photons $\mathrm{cm}^{-3} \mathrm{~s}^{-1}$ and the aurora at $250^{\circ}$ in Fig. 8(b) has disappeared, leaving a very deep minimum in emission rate, of about 40 photons $\mathrm{cm}^{-3} \mathrm{~s}^{-1}$ at $290^{\circ}$ longitude. In Fig. 10 we show the green line profiles from the region of maximum emission rate, and from near the minimum. In Fig. 10(a) for $99^{\circ}$ longitude the peak emission rate is slightly above 500 photons $\mathrm{cm}^{-3} \mathrm{~s}^{-1}$, an extremely high value, but even more remarkable, the topside of the profile extends to very high altitude, above $200 \mathrm{~km}$. If this is an airglow profile then it has been subject to an extreme dynamical influence. For the "auroral" longitude of $295^{\circ}$ shown in Fig. 10(b) we see a weak auroral profile peaking near $130 \mathrm{~km}$, indicating rather low energy auroral precipitation, and underneath it a very weak airglow profile, with a peak value of 25 photons $\mathrm{cm}^{-3} \mathrm{~s}^{-1}$. The emission rate gap between the bottom of the aurora and the top of the airglow is fully consistent with our knowledge of auroral and airglow profiles. Errors in the inversion of apparent data to volume emission rate can occur where the emission rates are not horizontally homeneous, which could happen for localized auroral features. However, since WINDII has two fields of view with orthogonal look directions, it is possible to compare orthogonal views, with a time delay of about 8 min and they are totally consistent in this case. Thus this profile, consisting of independent auroral and airglow profiles is considered to be valid. Thus on two sides of the polar cap, at the same latitude, we have airglow emission rate profiles with a peak emission rate ratio of 20 , indicating a truly remarkable dynamical influence that deserves further exploration.

The origins of this influence appear to involve a stratospheric warming located near the peak of the green line emission rate which was evident on February 16, 1993, and reached its peak warming value on February 18, 1993. The NMC temperature map for $5 \mathrm{hPa}$ is shown in Fig. 11. The maximum warming occurred at $70^{\circ}$ longitude and $60^{\circ}$ latitude, which the same latitude as for the green line observations, and only slightly shifted from the longitude of $100^{\circ}$ for the WINDII observations. This difference in longitude as well as the time delay of two days between the lower thermosphere and the stratosphere may well be consistent with the coupling processes involved, which need further examination. It is of interest to note that the springtime transition oxygen airglow emission rate enhancements shown in Fig. 4, for observations made from Stockholm and Bear Lake, also coincided with a stratospheric warming as reported by Naujokat et al. (1992) for March 25, 1992. This date marks the beginning of the airglow enhancement at Stockholm.

\section{Conclusions}

The influence of the diurnal tide on the oxygen airglow at the equator has been confirmed and extended through an examination of the hydroxyl airglow. At equinox, these airglows are out of phase but at solstice, where the diurnal tide is less dominant these airglow emission rates are more nearly 
in phase. The springtime transition is a transition between high winter and low summer values of atomic oxygen that takes place in about one week and is seen most clearly at high latitudes. At mid and low latitudes the dominant effect is the appearance of planetary scale waves which span the equator. Extremely large planetary scale disturbances may be seen at high latitudes during winter. Examination of one event leads to the tentative conclusion that it is the result of a stratospheric warming. The perturbation occurs about two days earlier in the lower thermosphere than in the stratosphere, and is shifted by about $30^{\circ}$ in longitude between the two levels.

A discussion of the possible connection between the stratospheric warming and the enhancement of $\mathrm{O}\left({ }^{1} \mathrm{~S}\right)$ emission in the lower thermosphere is beyond the scope of this paper. However we note that Dunkerton et al. (1981) provide a model demonstration of the coupling between the stratosphere and mesosphere; the stratospheric warming is accompanied by a mesospheric cooling. It therefore seems reasonable to expect coupling to the lower thermosphere as well, which is strongly implied by the WINDII observations, which indicate thermospheric downwelling in the region of the stratospheric warming, as part of a global-scale wave 1 . Dunkerton et al. (1981) point to observations that hint at preconditioning of the mean flow by the action of wave 1 , as a precursor to the involvement of wave 2 in a major warming. They thus suggest that the essential role of the wave 1 may be to change the mean flow in a way as to focus any upwardpropagating wave 2 into the polar cap. Whether the WINDII wave 1 observations are related to this wave 1 precursor is a matter that remains to be explored.

Acknowledgments. The WINDII project is supported by the Canadian Space Agency, and the Centre National d'Etudes Spatiales of France. Scientific analyses of the data are funded by the Natural Sciences and Engineering Research Council of Canada. Nikolas Pertsev first drew our attention to the date of February 15, 1993 as being anomalous in its airglow characteristics.

\section{References}

Angelats i Coll, M. and J. M. Forbes, Dynamical influences on atomic oxygen and $5577 \AA$ emission rates in the lower thermosphere, Geophys. Res. Lett., 25, 461-464, 1998.

Burrage, M. D., N. Arvin, W. R. Skinner, and P. B. Hays, Observations of the $\mathrm{O}_{2}$ atmospheric band nightglow by the High Resolution Doppler Imager, J. Geophys. Res., 99, 15017-15023, 1994.

Christophe-Glaume, J., Étude de la raie $5577 \AA$ de l'oxygene dans la luminescence atmosphèric nocturne, Ann. Geophys., 21, 1, 1965.

Cogger, L. L., R. D. Elphinstone, and J. S. Murphree, Temporal and latitudinal $5577 \AA$ airglow variations, Can. J. Phys., 59, 1296-1307, 1981.

Donahue, T. M., B. Guenther, and R. J. Thomas, Distribution of atomic oxygen in the upper atmosphere deduced from Ogo 6 airglow observations,
J. Geophys. Res., 78, 6662-6689, 1973.

Dunkerton, T., C.-P. F. Hsu, and M. E. McIntyre, Some Eulerian and Lagrangian diagnostics for a model stratospheric warming, J. Atmos. Sci., 38, 819-843, 1981.

McDade, I. C., et al., ETON 2: Quenching parameters for the proposed precursors of $\mathrm{O}_{2}\left(\mathrm{~b}^{1} \Sigma_{g}^{+}\right)$and $\mathrm{O}\left({ }^{1} \mathrm{~S}\right)$ in the terrestrial nightglow, Planet Space Sci., 34, 789-800, 1986.

McLandress, C., G. G. Shepherd, and B. H. Solheim, Satellite observations of thermospheric tides: results from the Wind Imaging Interferometer on UARS, J. Geophys. Res., 101, 4093-4114, 1996.

Naujokat, B., K. Petzoldt, K. Labitzke, R. Lenschow, B. Rajewski, M. Wiesner, and R.-C. Wohlfart, The stratospheric winter 1991/92, Beilage zur Berliner Wetterkarte, Wissenschaftliche Einrichtung 07 im Fachbereich Geowissenschaften der Freien Universitat Berlin, ISSN 0938-5312, 1992.

Reed, E. I. and S. Chandra, The global characteristics of atmospheric emissions in the lower thermosphere and their aeronomic implications, $J$. Geophys. Res., 80, 3053-3062, 1975.

Roble, R. G. and G. G. Shepherd, An analysis of Wind Imaging Interferometer observations of $\mathrm{O}\left({ }^{1} \mathrm{~S}\right)$ equatorial emission rates using the Thermosphere-Ionosphere-Mesosphere-Electrodynamics General Circulation Model, J. Geophys. Res., 102, 2467-2474, 1997.

Shepherd, G. G., et al., WINDII: The Wind Imaging Interferometer on the Upper Atmosphere Research satellite, J. Geophys. Res., 98, 10,72510,750, 1993.

Shepherd, G. G., C. McLandress, and B. H. Solheim, Tidal influence on $\mathrm{O}\left({ }^{1} \mathrm{~S}\right)$ airglow emission rate distributions at the geographic equator as observed by WINDII, Geophys. Res. Lett., 22, 275-278, 1995.

Shepherd, G. G., R. G. Roble, C. McLandress, and W. E. Ward, WINDII observations of the $558 \mathrm{~nm}$ emission in the lower thermosphere: the influence of dynamics on composition, J. Atmos. Solar-Terr. Phys., 59, 655-667, 1997.

Shepherd, G. G., R. G. Roble, S.-P. Zhang, C. McLandress, and R. H Wiens, Tidal influence on midlatitude airglow: Comparison of satellite and ground-based observations with TIME-GCM predictions, J. Geophys. Res., 103, 14741-14751, 1998.

Shepherd, G. G., J. Stegman, P. Espy, C. McLandress, G. Thuillier, and R. $\mathrm{H}$. Wiens, Springtime transition in lower thermospheric atomic oxygen, J. Geophys. Res., 104, 213-223, 1999.

Shepherd, M. G., R. L. Gattinger, Y. Rochon, G. G. Shepherd, B. H. Solheim, and D. J. W. Kendall, Auroral Observations with the WIND Imaging Interferometer (WINDII) on UARS, Adv. Space Res., 17, (11)5-(11)10, 1996.

Stegman, J., D. Murtagh, and G. Witt, Extremes of oxygen airglow intensity, Abstract SA22C-11, AGU Spring Meeting Program, Montreal, May, 1992.

Tohmatsu, T., Compendium of Aeronomy, translated by T. Ogawa, 509 pp., Terra Scientific Publishing Company, Tokyo, Kluwer Academic Publishers, Dordrecht, 1990.

Ward, W. E., A simple model of diurnal variations in the mesospheric oxygen nightglow, Geophys. Res. Lett., 1999 (in press).

Yudin, V. A., M. A. Geller, B. V. Khattatov, D. A. Ortland, M. D. Burrage, C. McLandress, and G. G. Shepherd, TMTM simulations of tides: Comparison with UARS observations, Geophys. Res. Lett., 25, 221-224, 1998.

Zhang, S. P. and G. G. Shepherd, The influence of the diurnal tide on the latitudinal distributions of the $\mathrm{O}\left({ }^{1} \mathrm{~S}\right)$ and $\mathrm{OH}$ emission rates observed by WINDII on UARS, Geophys. Res. Lett., 26, 529-532, 1999.

G. G. Shepherd (e-mail: gordon@windii.yorku.ca), S. Zhang, and X. Wang 